\title{
FoxO3 suppresses Myc-driven lymphomagenesis
}

\author{
CJ Vandenberg ${ }^{1,2}, \mathrm{~N}^{\text {Motoyama }}{ }^{3}$ and S Cory ${ }^{*, 1,2}$
}

This study demonstrates, for the first time, that loss of a single forkhead box class 0 (FoxO) transcription factor, can promote lymphomagenesis. Using two different mouse models, we show that $\mathrm{FoxO} 3$ has a significant tumour-suppressor function in the context of Myc-driven lymphomagenesis. Loss of FoxO3 significantly accelerated myeloid tumorigenesis in vavP-MYC10 transgenic mice and B lymphomagenesis in $\mathrm{E} \mu-m y c$ transgenic mice. Tumour analysis indicated that the selective pressure for mutation of the p53 pathway during E $\mathrm{\mu}-\mathrm{myc}$ lymphomagenesis was not altered. Frank tumours were preceded by elevated macrophage numbers in FoxO3 ${ }^{-l-}$ vavP-MYC10 mice but, surprisingly, pre-B-cell numbers were relatively normal in healthy young FoxO3 ${ }^{-l}-\mathrm{E \mu}$-myc mice. In vitro assays revealed enhanced survival capacity of Myc-driven cells lacking FoxO3, but no change in cell cycling was detected. The loss of FoxO3 may also be affecting other tumour-suppressive functions for which Fox01/4 cannot fully compensate.

Cell Death and Disease (2016) 7, e2046; doi:10.1038/cddis.2015.396; published online 14 January 2016

The evolutionarily conserved forkhead box class O (FoxO) transcription factors have important roles in cellular metabolism, stress tolerance and probably lifespan., ${ }^{1,2}$ They are key regulators of cell proliferation and survival, a large number of their transcriptional targets being involved in apoptosis, ${ }^{3-5}$ cell cycle arrest, ${ }^{6,7}$ DNA repair, oxidative stress resistance and metabolic processes. ${ }^{8,9}$

Regulation of FoxOs is complex, involving acetylation and ubiquitination as well as phosphorylation (reviewed in Eijkelenboom and Burgering ${ }^{10}$ ). Under normal conditions of growth factor signalling, FoxO transcription factors are inactivated through phosphorylation by activated AKT. For FoxO3 this occurs at three conserved residues (Thr-32, Ser-253 and Ser-315), resulting in the export of $\mathrm{FoxO} 3$ from the nucleus into the cytoplasm ${ }^{11}$ and proteasomal degradation. ${ }^{12}$ During conditions of oxidative stress, nuclear translocation and activation of FoxOs occurs through Jun $\mathrm{N}$-terminal kinase phosphorylation, which overrides growth factor signalling. ${ }^{13}$

The FoxOs are highly related and to some degree can act redundantly as they bind to the same consensus sequence. ${ }^{14}$ Of the four mammalian FoxO family members, $\mathrm{FoxO} 1$, $\mathrm{FoxO} 3$ and FoxO4 are widely expressed, ${ }^{14}$ whereas FoxO6 is mainly expressed in adult brain tissue. ${ }^{15}$ In haemopoietic tissues, FoxO1 and FoxO3 are the major FoxOs, with FoxO1 levels highest in lymphoid cells and FoxO3 levels highest in myeloid cells. ${ }^{16}$

Although $\mathrm{FoxO}^{-1-}$ mice do not have an obvious phenotype, ${ }^{17}$ FoxO6 $^{-1-}$ mice show impaired memory consolidation ${ }^{18}$ and deletion of FoxO1 results in defects in embryonic vascular development, resulting in death at embryonic day 10.5. ${ }^{17,19}$ FoxO3-deficient mice display early onset female infertility because of depletion of ovarian follicles caused by widespread follicular activation. ${ }^{17,20}$ Aged FoxO3-1- mice were found to have reduced numbers of haemopoietic stem cells (HSCs), ${ }^{21}$ implying that $\mathrm{FoxO} 3$ contributes to the maintenance of the HSC pool during aging by reducing oxidative stress. ${ }^{22}$ FoxO3 primes HSCs for metabolic stress (starvation)-induced autophagy, which is necessary for HSC survival. ${ }^{23}$

Activation of AKT, and thus inactivation of FoxOs, is frequently observed in a range of cancers, ${ }^{24}$ raising the possibility that FoxO proteins may serve as tumour suppressors. An early study found that loss of individual FoxOs did not cause cancer predisposition, except for loss of FoxO1. ${ }^{17,20}$ When FoxO1 was deleted using Mx-Cre (at 4 weeks of age), mice developed systemic hemangiomas, but with long latency and low frequency. ${ }^{25}$ However, compound somatic deletion of three FoxOs, FoxO1/3/4, resulted in thymic lymphomagenesis. ${ }^{25}$ Furthermore, a dominant-negative FoxO construct, which expresses the conserved DNA-binding domain of FoxO4 but lacks the transactivation domain and thus inhibits the activity of all FoxOs, greatly accelerated the onset of E $\mu$-myc lymphomas. ${ }^{26}$ This effect is due, at least in part, to FoxO upregulation of p19 $9^{\mathrm{ARF}}$ expression, which promotes p53-dependent apoptosis. In fact, the dominant-negative

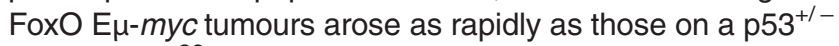
background. ${ }^{26}$ FoxO3 and MYC compete for binding to some promoters and appear to antagonise each other's activity. ${ }^{27-29}$ FoxO3 directly regulates expression of the MYC inhibitor MXI1, whereas other Max-interacting protein (MXD) family members are regulated indirectly. ${ }^{30}$

To determine whether loss of a single FoxO can cooperate in Myc-driven tumorigenesis, we crossed $\mathrm{FoxO}^{-/-}$mice $^{21}$ with vavP-MYC10 mice, which express the transgene in all haemopoietic lineages and primarily develop myeloid tumours with some T lymphomas, ${ }^{31,32}$ and with $\mathrm{E} \mu$-myc mice, which

\footnotetext{
${ }^{1}$ Molecular Genetics of Cancer Division, The Walter and Eliza Hall Institute of Medical Research, Melbourne, Victoria, Australia; ${ }^{2}$ Department of Medical Biology, University of Melbourne, Melbourne, Victoria, Australia and ${ }^{3}$ Department of Human Nutrition, Sugiyama Jogakuen University School of Life Studies, Chikusa-ku, Nagoya, Aichi, Japan *Corresponding author: S Cory, Molecular Genetics of Cancer Division, The Walter and Eliza Hall Institute of Medical Research, 1G Royal Parade, Parkville, VIC 3052 , Australia. Tel: +61 3 93452492; Fax: +61 3 93470852; E-mail: cory@ wehi.edu.au

Abbreviations: dnFoxO, dominant-negative FoxO; FACS, fluorescence-activated cell sorting; FoxO, Forkhead-box O class; HSC, haemopoietic stem cell; IHC, immunohistochemistry; IL-2, interleukin 2; IL-7, interleukin 7; PI, propidium iodide; slg, surface immunoglobulin; WBC, white blood cell; WT, wild type.

Received 23.11.15; accepted 04.12.15; Edited by G Melino
} 
constitutively express Myc in B lymphoid cells and are susceptible to pre-B and B lymphomas. ${ }^{33,34}$

\section{Results}

Loss of FoxO3 accelerates Myc-driven tumorigenesis. vavP-MYC10 (hereafter MYC10) transgenic mice develop macrophage tumours with a median onset of approximately 300 days. Lymphomagenesis was significantly accelerated by the loss of FoxO3, all FoxO3 ${ }^{-1}-M Y C 10$ mice having succumbed to disease by 300 days compared with 400 days for the MYC10 mice (Figure 1a) (median survival of FoxO3-1MYC10 256 days versus 295 days for MYC10; $P<0.0001$ ). Comparison of spleen weights and white blood cell (WBC) counts of tumour-bearing mice showed that the tumour burden was higher in the FoxO3 ${ }^{-1-}$ MYC10 mice (Figures $1 \mathrm{~b}$ and c). The tumour phenotype (Figure 1d) was comparable between the cohorts, being predominantly monocyte/macrophage tumours $\left(\mathrm{Mac} 1^{+} \mathrm{F} 4 / 80^{+}\right)$with a small proportion of T-cell tumours (Thy $1^{+} \mathrm{CD}^{+}$and variable CD4 and CD8 expression), as previously reported for MYC10 mice. ${ }^{32}$ Tumours of all genotypes were transplantable in C57BL/6 recipients ( $n=9-12$ independent tumours).

When we assessed the impact of FoxO3 loss on lymphomagenesis in $\mathrm{E} \mu-m y c$ mice, again we found a significant acceleration in morbidity. The median survival of FoxO3 ${ }^{-1} \mathrm{E} \mu-$ myc mice was 93 versus 125 days for $\mathrm{E} \mu$-myc mice $(P<0.0001)$, with no FoxO3 ${ }^{-/} \mathrm{E} \mu-m y c$ mice surviving beyond 150 days (Figure 2a). Tumour-bearing mice typically presented with enlarged spleen, lymph nodes and/or thymus, with no significant difference in lymphoma burden between genotypes (Figures $2 \mathrm{~b}$ and $\mathrm{c}$ ). Although $\mathrm{E} \mu-m y c$ mice
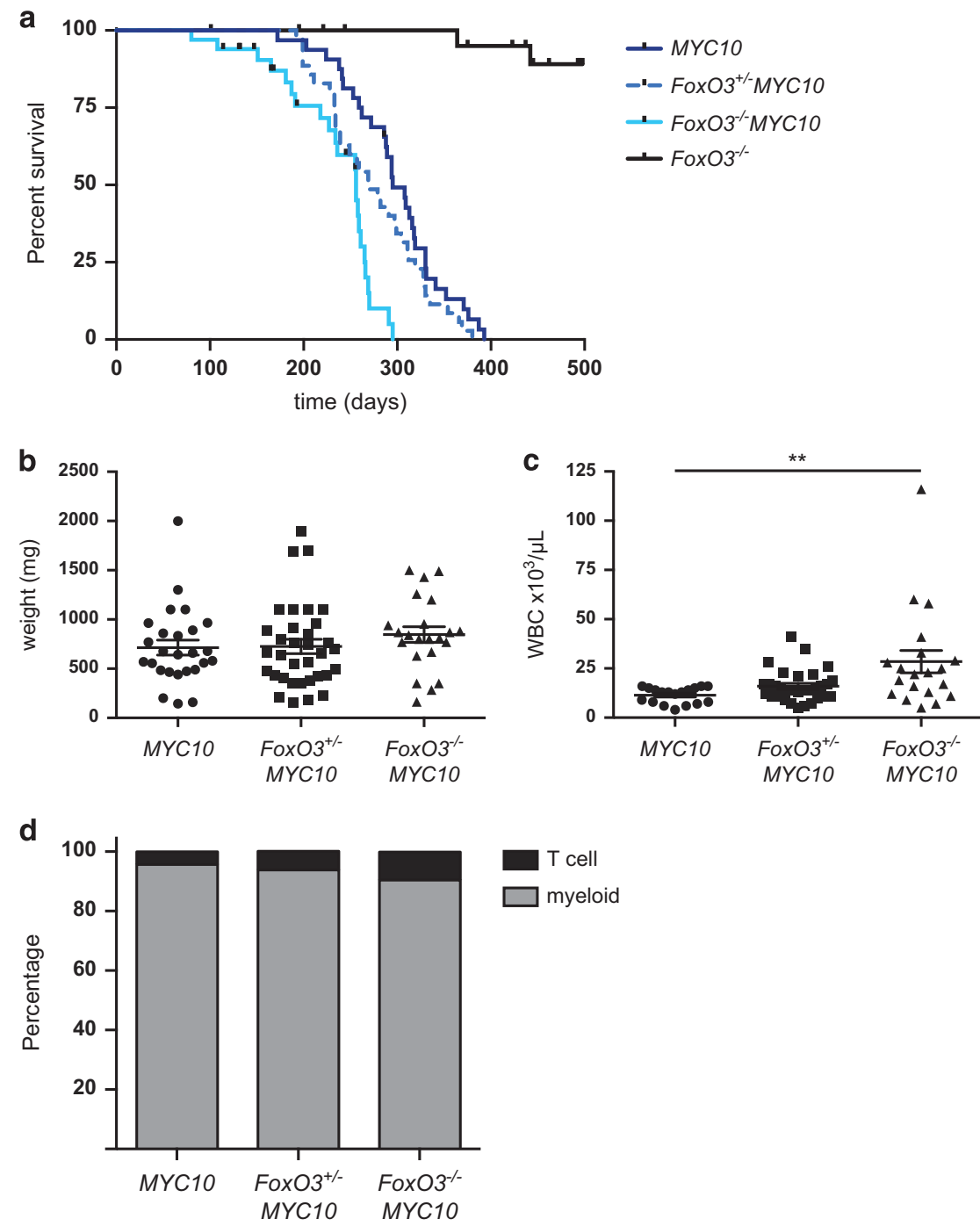

Figure 1 Loss of FoxO3 accelerates Myc-induced myeloid tumorigenesis. (a) Kaplan-Meier survival curves for MYC10 ( $n=32$, median survival 295 days), FoxO3 ${ }^{+/-}$MYC10 ( $n=35$, median survival 270 days), FoxO3 ${ }^{-1-}$ MYC10 $(n=33$, median survival 256 days) and FoxO3-1- $(n=24)$. Non-tumour-related deaths have been censored. Tumorigenesis is significantly accelerated in FoxO3 ${ }^{-1}$ MYC10 versus MYC10 mice, $P<0.0001$, log-rank test. (b) Spleen weights and (c) WBC counts of sick mice. Leukocytes were elevated in FoxO3 ${ }^{-1-}$ MYC10 mice, ${ }^{* *} P<0.01$, Student's t-test. (d) Proportions of myeloid and T-cell tumours in sick mice. Tumour cell suspensions were stained for cell surface markers and analysed by FACS. $n=22-32$ 
a

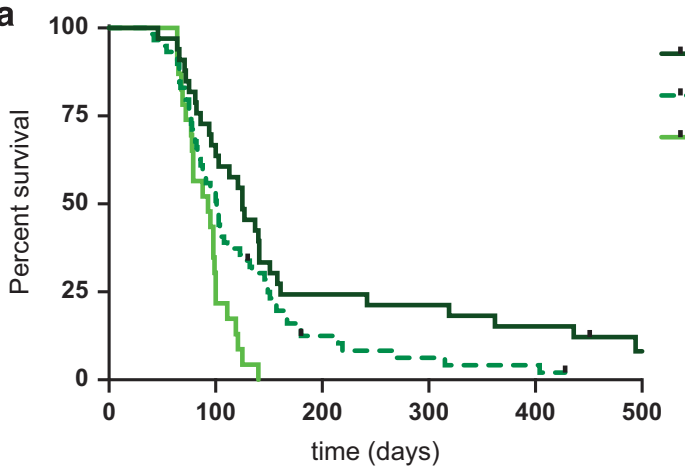

+ $\mathrm{E} \mu-m y c$
- $\mathrm{FoxO}^{+/} \mathrm{E} \mu-m y c$
- $\mathrm{FoxO}^{-/-} \mathrm{E} \mu-m y c$

b

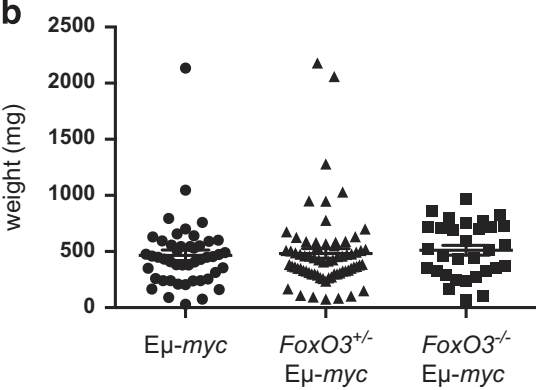

C

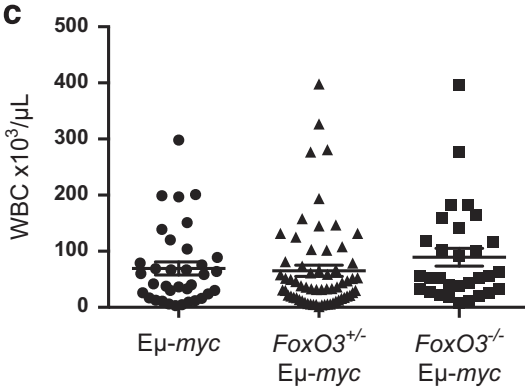

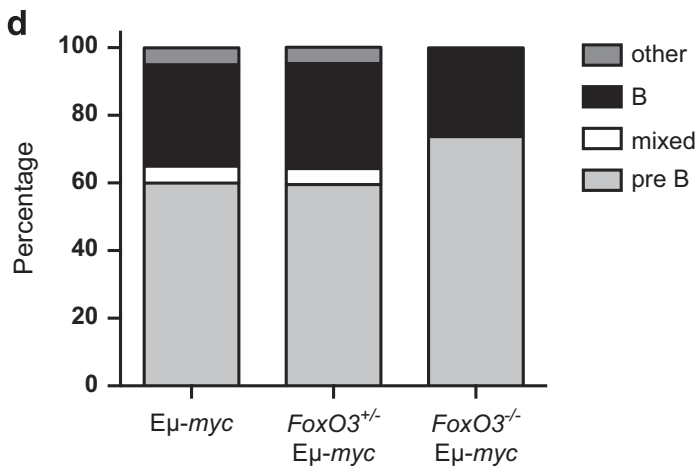

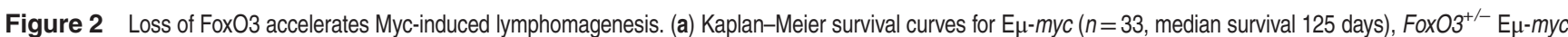
( $n=59$, median survival 101 days) and FoxO3-1- $\mathrm{E} \mu-m y c(n=23$, median survival 93 days). Non-tumour-related deaths have been censored. Lymphomagenesis is significantly

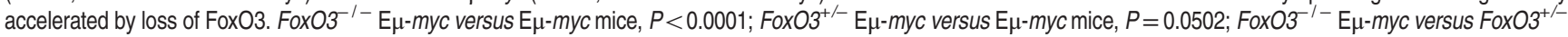
$E \mu-m y c, P=0.0076$; log-rank test. (b) Spleen weights and (c) WBC counts of sick mice. (d) Proportions of pre-B, mixed (pre-B/B), B and other lymphoid (Tor primitive) tumours in sick mice; determined by staining for cell surface markers and FACS analysis. $n=20-42$

generally succumb to $\operatorname{sigM}^{-} \mathrm{B} 220^{+}$pre-B lymphomas or slgM ${ }^{+} \mathrm{B} 220^{+}$B-cell lymphomas, ${ }^{33,34}$ certain crosses have led to changes in tumour phenotype, either predominantly B-cell lymphomas (e.g., in $\mathrm{p} 53^{+/-} / \mathrm{E} \mu-m y c$ and vavP-Mcl-1/E $\mu-m y c$ mice), ${ }^{35,36}$ or a complete change in immunophenotype (e.g., in $\mathrm{E} \mu-b c l-2 / \mathrm{E} \mu-m y c$ and $\mathrm{E} \mu-\mathrm{v}-a b / / \mathrm{E} \mu-m y c$ mice). ${ }^{37,38}$ However, immunophenotyping of the FoxO3 ${ }^{-1}$ E $\mu-m y c$ lymphomas revealed no major difference in the proportion of pre$B$ versus B-cell tumours compared with $\mathrm{E} \mu-m y c$ lymphomas (Figure 2d).

Haemopoietic homeostasis is perturbed by loss of Fox03. To determine whether loss of FoxO3 alters the preneoplastic phenotype of MYC10 mice, which could contribute to the enhanced tumorigenesis, we compared the composition of blood and haemopoietic tissues of healthy mice at 8 weeks of age (Figure 3, Supplementary Figure 1 and Supplementary Table 1).

Perhaps surprisingly, loss of FoxO3 alone had a greater impact on haemopoietic homeostasis than expression of the MYC10 transgene, which provokes only a mild preneoplastic phenotype. ${ }^{32}$ The FoxO3 ${ }^{-1-}$ mice had significantly increased T cells in the spleen and blood, but not in lymph nodes. Herold et al. ${ }^{39}$ have also reported an increase in splenic T cells using the same FoxO3 $3^{-1-}$ mice, although increased T-cell numbers were not observed in an earlier study using a different line. ${ }^{40}$ Consistent with previous reports, the FoxO3 ${ }^{-1}$ mice also had increased myeloid cells in the spleen and bone marrow, ${ }^{21,41,42}$ reduced recirculating $B$ cells in the bone marrow ${ }^{43}$ and elevated immature erythroid cells $\left(\right.$ Ter $\left.119^{+}\right)$, presumably due to impaired maturation. ${ }^{44,45}$

In general, the phenotype of $\mathrm{FoxO}^{-1-} \mathrm{MYC10}$ mice resembled that of $\mathrm{FOXO}^{-/-}$mice. However, in the spleen, 

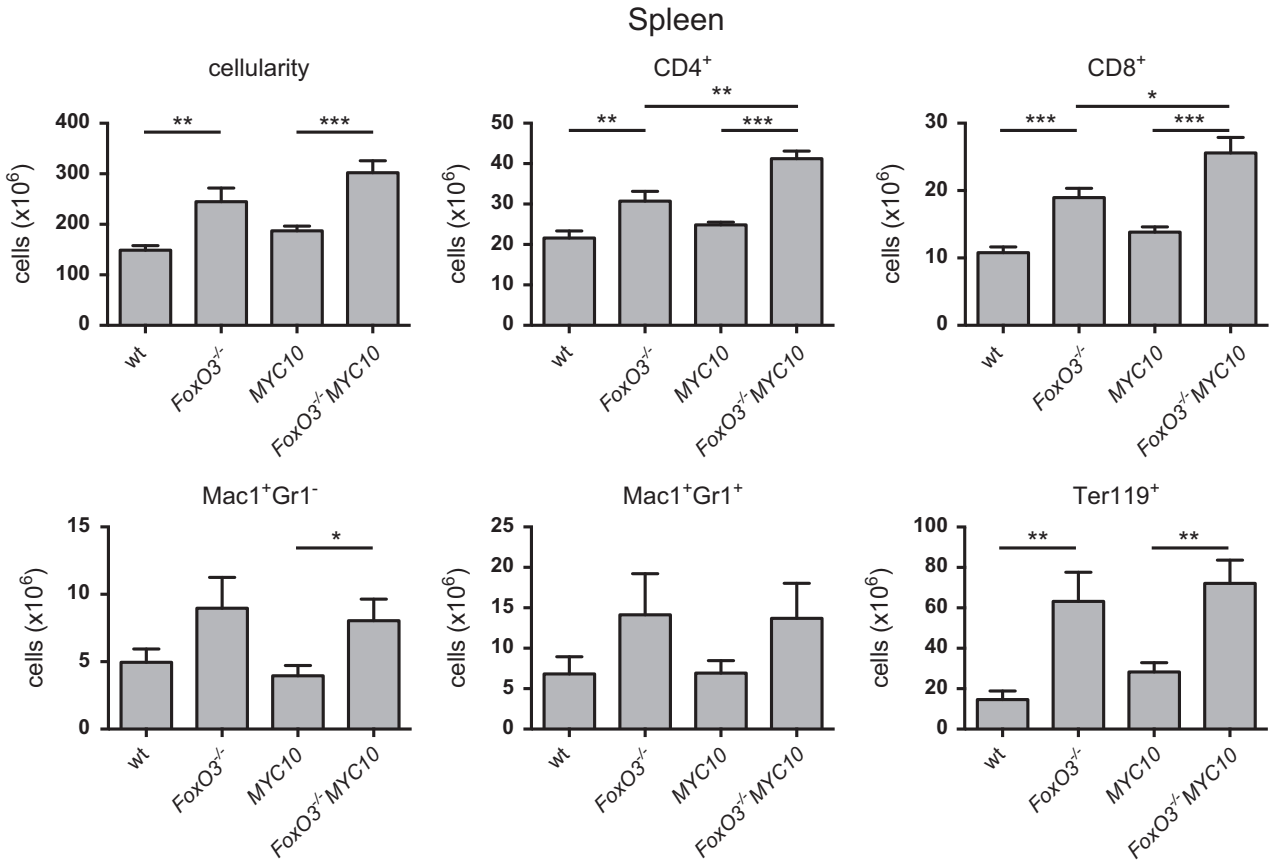

Figure 3 Loss of FoxO3 increases myeloid and T-cell populations in MYC10 mice. Enumeration of total leukocytes and indicated populations in the spleen of preneoplastic 8-week-old male mice ( $n=8-9$ per genotype). Bars represent mean \pm S.E.M.; statistical significance is shown only for WT versus FoxO3 ${ }^{-1-}$, MYC10 versus FoxO3 $^{-1}-M^{2}$ YC10 and FoxO3 ${ }^{-1-}$ versus FoxO3 ${ }^{-1-}$ MYC10 $\left({ }^{\star} P<0.05,{ }^{* \star} P<0.01,{ }^{* \star \star} P<0.001\right.$, Student's $t$-test). See also Supplementary Table S1 and Supplementary Figure 1

there was an additional increase in the number of $\mathrm{T}$ cells in FoxO3 ${ }^{-1}$ MYC10 mice compared with $\mathrm{FoxO}^{-1-}$ mice (Figure 3). Significant increases in myeloid populations were also observed in the blood, spleen and bone marrow, in particular $\mathrm{Mac1}^{+} \mathrm{Gr1}^{-}$cells, which were elevated approximately 2- to 2.5-fold in each organ (Figure 3, Supplementary Figure 1). As the majority of tumours arising in the MYC10 mice are $\mathrm{Mac1}^{+} \mathrm{Gr}^{-}$, it is likely that the increase in this population in $\mathrm{FoxO}^{-1-} \mathrm{MYC10}$ mice is a factor in the acceleration of tumour onset.

Haemopoietic analysis of pre-leukaemic $\mathrm{FoxO}^{-1-} \mathrm{E} \mu-m y c$ mice and littermates was performed at 4 weeks of age (Figure 4, Supplementary Figure 2 and Supplementary Table 2). Loss of FoxO3 resulted in increased myeloid cells in the blood, spleen and bone marrow of E $\mu-m y c$ mice, as in MYC10 mice, but no significant differences were seen in T-cell numbers. As E $\mu-m y c$ and $\mathrm{FoxO}^{-1-} \mathrm{E} \mu-m y c$ mice develop pre$\mathrm{B}$ or $\mathrm{B}$-cell lymphomas, the impact of $\mathrm{FoxO} 3$ loss on $\mathrm{B}$ lymphopoiesis was of particular interest. As documented previously, ${ }^{46}$ young preneoplastic $\mathrm{E} \mu$-myc mice had a greatly expanded pre-B-cell $\left(\mathrm{B}_{2} 20^{+} \mathrm{lgM} \mathrm{g}^{-} \mathrm{lg} \mathrm{D}^{-}\right)$population, with $15-$ to 20 -fold increases in the spleen, blood and lymph nodes, and there was a modest further increase in the blood of $\mathrm{FoxO}^{-1} \mathrm{E} \mu$-myc mice.

Cell cycle analysis. Deregulation of c-myc promotes tumorigenesis through altered expression of genes regulating cell cycling and proliferation. ${ }^{47}$ Loss of FoxO may be expected to amplify the cell cycle impact of myc, as $\mathrm{FoxO} 3$ regulates genes that promote cell cycle arrest. ${ }^{6,48}$ We tested this possibility in preneoplastic populations, to avoid the complication of additional oncogenic mutations.
As the $\mathrm{MYC10}$ and $\mathrm{FoxO}^{-1-} \mathrm{MYC10}^{-}$mice are predisposed to myeloid tumours, we analysed the cell cycle profiles of bone marrow macrophages and granulocytes from healthy young mice. No differences in the cell cycle distribution were detectable in either Mac1 $1^{+} \mathrm{Gr}_{1}^{-}$or Mac1 ${ }^{+} \mathrm{Gr}^{+}$cells (Figure 5).

For the $\mathrm{E} \mu-\mathrm{myc}$ and $\mathrm{FoxO}^{-1-} \mathrm{E} \mu-m y c$ mice, preneoplastic pre-B cells were analysed immediately after isolation from the bone marrow and also during culture in simple medium lacking exogenous cytokines. However, there was no difference between $\mathrm{E} \mu-m y c$ and $\mathrm{FoxO}^{-1} \mathrm{E} \mu-m y c$ pre-B-cell cycle profiles either before culture (first panel, Figure 6a) or at any of the time points analysed $(4 \mathrm{~h}, 8 \mathrm{~h}, 24 \mathrm{~h}$; Figure $6 \mathrm{a})$. Furthermore, tumour cells isolated from $\mathrm{E} \mu-m y c$ and FoxO3 ${ }^{-1-} \mathrm{E} \mu-m y c$ mice had similar cell cycle profiles (Figure 6b).

Impact of loss of FoxO3 on apoptosis of Mycoverexpressing cells. The proliferative effect of Myc overexpression is partially counteracted by Myc-driven apoptosis. ${ }^{49,50}$ We therefore investigated whether loss of FoxO3 inhibited apoptosis of cells overexpressing Myc. We reasoned that the impact of loss of FoxO3 may become more apparent during culture, as the deficiency in cytokine signalling would normally inactivate AKT and activate FoxO3.

As expression of the vavP-MYC transgene is highest in thymocytes ${ }^{32}$ we isolated the four major thymocyte populations by flow cytometry from wild-type (WT), $\mathrm{FoxO}^{-1-}$, MYC10 and $\mathrm{FoxO}^{-1-} \mathrm{MYC10}$ mice and cultured them in simple medium (i.e., in the absence of cytokines) either immediately (Supplementary Figure 3A) or following exposure to $1.25 \mathrm{~Gy} \gamma$-irradiation (Supplementary Figure $3 \mathrm{~B}$ ). For double-positive thymocytes, the most sensitive population, 
Blood
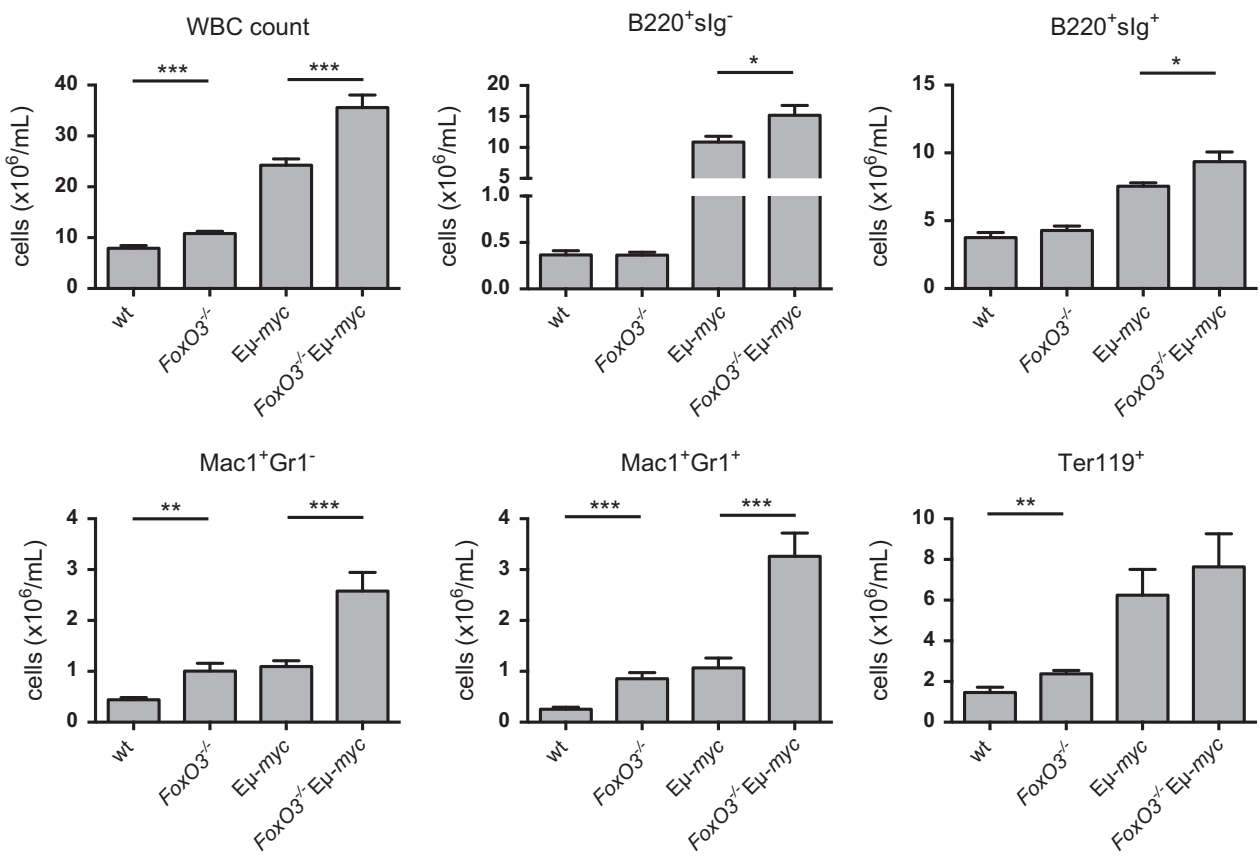

Figure 4 Loss of FoxO3 increases myeloid and B-cell populations in the blood of $\mathrm{E \mu}-\mathrm{myc}$ mice. Total WBC count and quantification of the indicated populations in the blood of preneoplastic 4-week-old male mice ( $n=8-9$ per genotype). Bars represent mean \pm S.E.M.; statistical significance is shown only for WT versus FoxO3 ${ }^{-1-}$ and E $\mu$-myc versus FoxO3 ${ }^{-1-}$ E $\mu-m y c\left({ }^{\star} P<0.05,{ }^{* \star} P<0.01,{ }^{* \star} P<0.001\right.$, Student's $t$-test). See also Supplementary Table S2 and Supplementary Figure 2
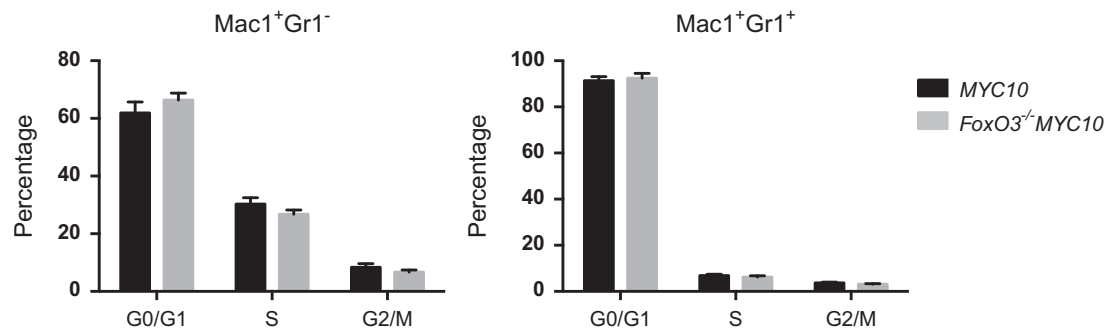

Figure 5 Loss of FoxO3 has no impact on the cycling of preneoplastic MYC10 myeloid cells. Bone marrow from MYC10 and FoxO3-1- $\mathrm{MYC10}^{-10}$ mice was surface stained with Mac1 and $\mathrm{Gr} 1$ before fixation. Cell cycle analysis of macrophages $\left(\mathrm{Mac1}^{+} \mathrm{Gr}^{-}\right.$) and granulocytes (Mac1 ${ }^{+} \mathrm{Gr}^{+}$) was then performed following incubation with PI/RNase staining solution. Data represent mean \pm S.E.M.; $n=6-7$ per genotype

there was a trend toward an increased viability of $\mathrm{FoxO}^{-1-}$ compared with WT cells under these conditions, but this was not apparent on the MYC10 background. Loss of FoxO3 also enhanced the survival of peripheral T-cell blasts following removal of interleukin 2 (IL-2), as noted previously, ${ }^{39}$ and this was evident even in the face of expression of the MYC10 transgene (Supplementary Figure $3 \mathrm{C}$ ).

Apoptosis was also assessed for B lymphoid cells from $\mathrm{E} \mu-m y c$ and FoxO $^{-1-} \mathrm{E} \mu-m y c$ mice. Frank tumours had comparable numbers of apoptotic cells (Figure 7a and Supplementary Figure 4). When pre-leukaemic pre-B cells sorted from bone marrow were cultured in the absence of cytokines, no significant survival advantage could be detected for those lacking FoxO3 (Figure 7b). However, when IL-7 was removed from IL-7-supported cultures of pre-B cells, loss of FoxO3 significantly enhanced the survival of $\mathrm{E} \mu-m y c$ (but not WT)
pre-B cells (Figure 7c). As IL-7 has a critical role in early B lymphopoiesis, this protective effect may account for the modest increase in pre-B cells in Fox $\mathrm{F}^{-1-} \mathrm{E} \mu$-myc compared with $\mathrm{E} \mu$-myc mice (Figure 4, Supplementary Table 2).

Loss of FoxO3 does not select against inactivation of the p53 pathway. Lymphomas arising in $\mathrm{E} \mu-m y c$ mice commonly bear mutations that inactivate the p19Arf/Mdm2/p53 pathway, either by $p 53$ mutation or deletion, p19Arf deletion, or overexpression of Mdm2. ${ }^{51}$ Although expression of dominant-negative FoxO (dnFoxO) reduced selective pressure to inactivate the p19Arf/p53 pathway during lymphomagenesis in $\mathrm{E} \mu-m y c$ mice ${ }^{26}$ this was not the case for FoxO3-l-E $\mathrm{F}-\mathrm{myc}$ lymphomas (Figure 8). One FoxO3 $^{-1-} \mathrm{E} \mu$-myc tumour (\# 81) had high levels of p53 and p19Arf, suggestive of a p53 inactivating mutation (as carried 
a
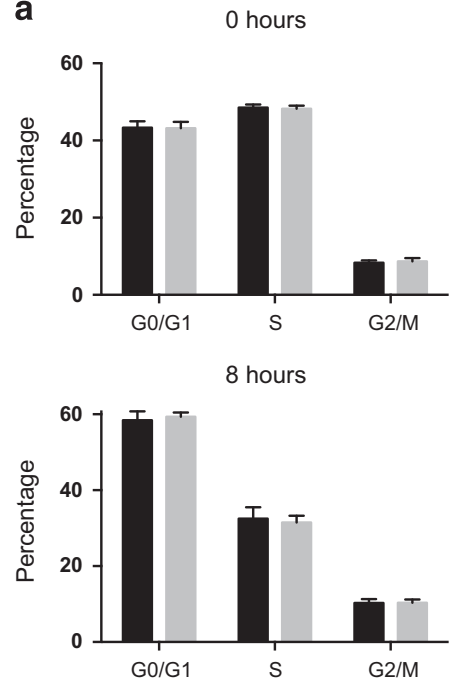

b

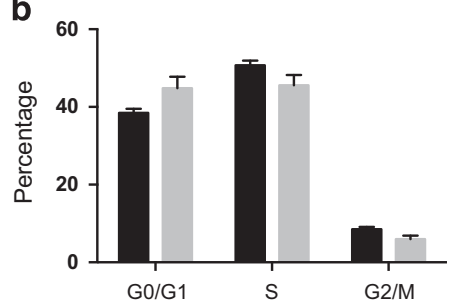

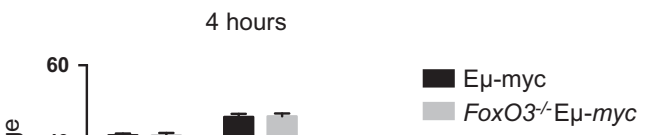

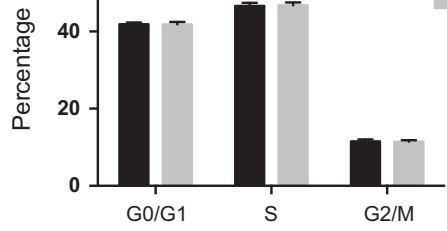

24 hours

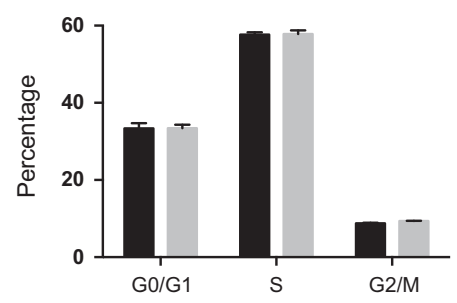

Figure 6 Loss of FoxO3 has no impact on the cycling of preneoplastic and neoplastic E $\mu-m y c$ pre-B cells. (a) Pre-B cells (B220 ${ }^{+}$slg $^{-}$) were purified from the bone marrow of 4-week-old $\mathrm{E} \mu$-myc and $\mathrm{FoxO}^{-1-} \mathrm{E} \mu$-myc mice by flow cytometry and cultured without cytokines. Cell cycle analysis was performed using Nicoletti staining at the indicated time points and flow cytometry. Cell cycle phases were determined using the Watson pragmatic model within the flow cytometry data analysis software FlowJo. Bars represent mean \pm S.E.M.; $n=4-5$ per genotype. (b) Pre-B/B cells were purified from tumours of E $\mu$-myc and FoxO3-1- E $\mu$-myc mice using CD19 beads and MACS columns. Cells were fixed then stained with PI/RNase staining solution. Cell cycle populations were analysed by FACS. Bars represent mean \pm S.E.M.; $n=5$ per genotype

by the positive control, Eu-myc lymphoma \#22). Certain other FoxO3 ${ }^{-1}$ E $\mu$-myc lymphomas (\#322 and \#430) had high levels of p19Arf but expressed no p53, apparently because of upregulation of Mdm2. Two, perhaps three, other FoxO3-1 -E $\mu-m y c$ lymphomas lacking p53 expression had elevated Mdm2 but did not express p19Arf (\#124, \#240 and perhaps \#94), suggestive of p19Arf deletion, as observed previously. ${ }^{51}$ Thus, overall, 5 or 6 of 13 (38-46\%) FoxO3-1-E $\mu$-myc lymphomas analysed showed evidence of loss of p53 or Arf function, comparable to the 13/25 (52\%) reported by Eischen et al..$^{51}$ Thus, the absence of $\mathrm{FoxO} 3$ alone appears insufficient to select against inactivation of the p53 pathway.

\section{Discussion}

We have demonstrated, for the first time, that loss of a single FoxO transcription factor, can promote lymphomagenesis. Whereas Paik et al. ${ }^{25}$ found that complete loss of FoxO activity (both alleles of FoxO1, $\mathrm{FoxO} 3$ and $\mathrm{FoxO} 4$ ) is required for lymphomagenesis, we have shown using two different mouse models that loss of FoxO3 alone suffices to accelerate Mycdriven lymphomagenesis. In the absence of FoxO3, myeloid tumours arose more rapidly in vavP-MYC10 mice and pre-B and $B$ lymphomas arose more rapidly in $E \mu-m y c$ transgenic mice (Figures 1 and 2). Unsurprisingly, the reduction in tumour latency was not as great as that observed when a dominantnegative FoxO construct was used to inhibit all FoxOs in the E $\mu$-myc model. ${ }^{25}$ Deficiency in a single FoxO does not have an observable effect in all tumour models, however, as loss of FoxO3 or FoxO4 does not accelerate or increase the incidence of DMBA-induced tumorigenesis. ${ }^{25}$

The larger population of myeloid cells in FoxO3-deficient MYC10 mice is likely to be a significant factor contributing to accelerated myeloid tumour formation in this model (Figure 3, Supplementary Figure 1 and Supplementary Table 1). In the $\mathrm{E} \mu-m y c$ model, expansion of the pre-B-cell pool, although modest, may contribute to accelerated lymphoma development in the absence of FoxO3.

Several factors may contribute to increasing the size of the susceptible populations. The absence of $\mathrm{FoxO} 3$ had no discernible impact on the cycling of pre-leukaemic myeloid cells isolated from MYC10 mice (Figure 5) or of pre-leukaemic or neoplastic B lymphoid cells taken from E $\mathrm{\mu}$-myc mice (Figure 6). Presumably other FoxOs can compensate in this role - FoxO1, in particular, was readily detected in lymphoid cells from E $\mu-m y c$ and vavP-MYC mice (Supplementary Figure 5), as reported previously for WT lymphoid cells. ${ }^{16}$ Previous studies have reported that FoxO3-deficiency increased the viability of mast cells and thymocytes cultured in the absence of cytokines ${ }^{39,52}$ and we were able to demonstrate enhanced viability of certain T-cell populations from 

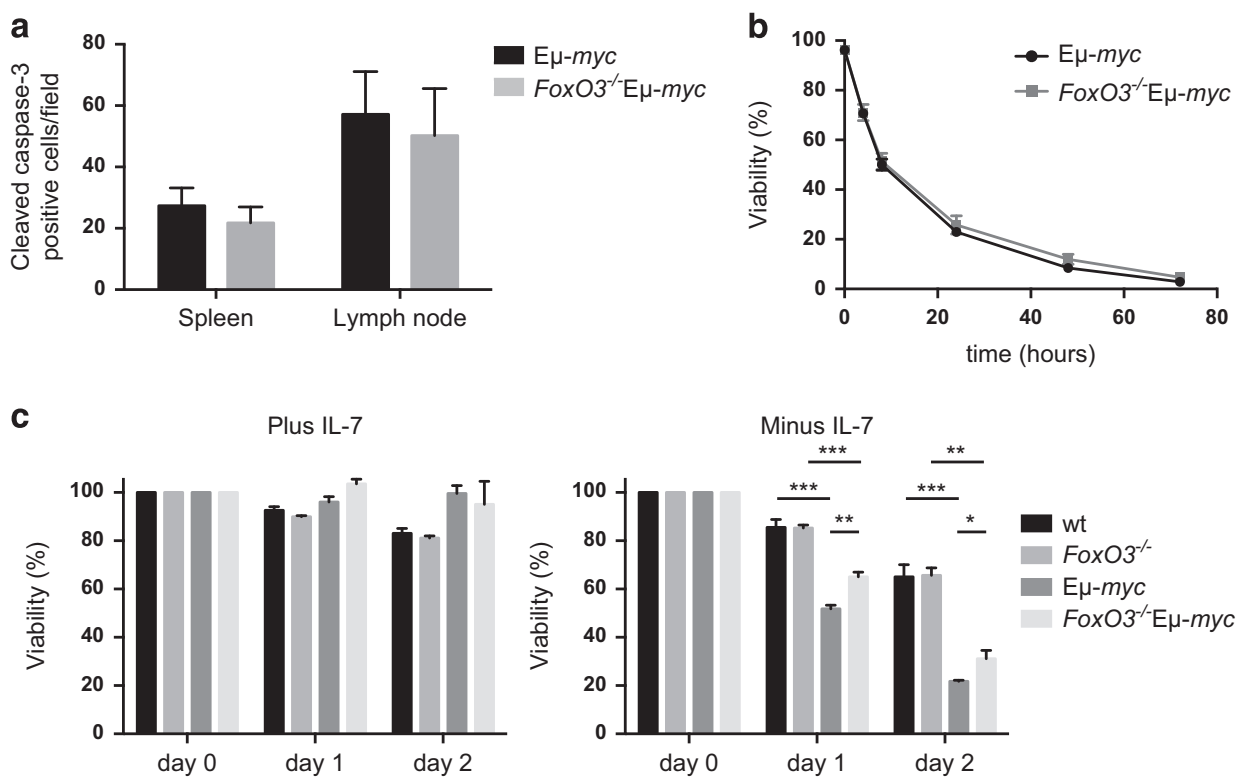

Figure 7 Impact of loss of $\mathrm{FoXO} 3$ on the apoptosis of preneoplastic and neoplastic E $\mu$-myc cells. (a) Quantification of cleaved caspase-3 positive cells in the spleen and

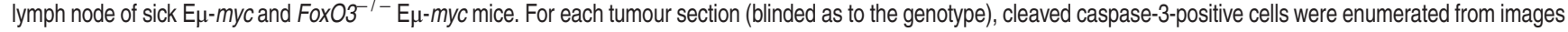
of three independent fields of view at $\times 200$ magnification. Bars represent mean \pm S.E.M.; $n=4-6$ per genotype. (b) Spontaneous death of FACS purified preneoplastic pre-B cells $\left(\mathrm{B}_{22} \mathrm{O}^{+} \mathrm{slg}\right.$ ) from 4-week-old $\mathrm{E} \mu$-myc and FoxO3 ${ }^{-1-} \mathrm{E} \mu$-myc mice cultured in simple medium (no cytokines) was assessed by staining with PI and annexin V followed by FACS analysis ( $n=5-6$ per genotype). Values represent mean \pm S.E.M. (c) Enhanced survival upon IL-7 withdrawal of cultured FoxO3-1- E $\mu-m y c$ pre-B cells. Pre-B cells isolated from bone marrow of mice of the indicated genotypes were cultured in the presence of $2 \%$ IL-7 supernatant for 5 days. Survival following removal of IL-7 was determined at the indicated time points by flow cytometry, with data normalised to the viability of each culture when IL-7 was withdrawn, day 0 . Bars represent mean \pm S.E.M.; $n=3-4$ mice for each

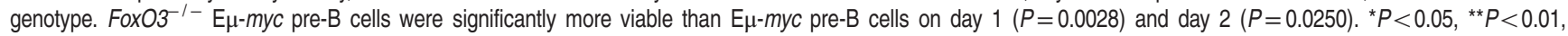
${ }^{* * \star} P<0.001$, Student's $t$-test

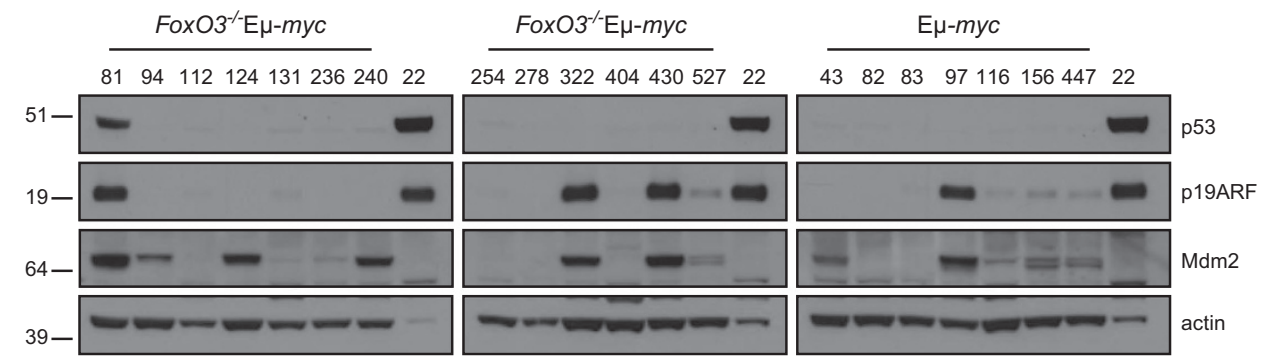

Figure 8 Loss of FoxO3 does not relieve the pressure for mutation of the p53 pathway in E $\mu$-myc lymphomagenesis. Western blot analysis of p53, p19ARF and Mdm2 in the

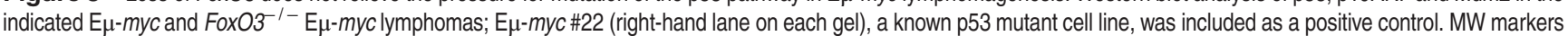

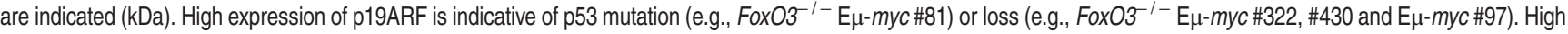
expression of Mdm2 promotes ubiquitinylation and degradation of $\mathrm{p} 53$, thereby abrogating p53-mediated apoptosis

vavP-MYC10 mice, particularly after cytokine removal (Supplementary Figure 3). Similarly, lack of FoxO3 enhanced the viability of cultured $\mathrm{E} \mu-m y c$ pre-B cells following IL-7 removal (Figure 7c). Reduced apoptosis has also been documented in dnFoxO-expressing $\mathrm{E} \mu$-myc lymphoma cells. $^{26}$

Activation of $\mathrm{p53}$ is a principal route for Myc-induced apoptosis. Myc upregulates p19Arf expression, probably indirectly, and p19Arf binds to and neutralises Mdm2, thereby preventing inhibition and degradation of p53 and facilitating expression of pro-apoptotic p53 targets, $\mathrm{BH}$-only proteins Puma and Noxa and, in a negative feedback loop, Mdm2. ${ }^{53}$ Although expression of dnFoxO reduced the selective pressure to inactivate the p19Arf/p53 pathway during lymphomagenesis in $\mathrm{E} \mu-m y c$ mice, ${ }^{26}$ this was not the case for FoxO3 $^{-1-} \mathrm{E} \mu$-myc lymphomas (Figure 8).

In summary, we have demonstrated using two different mouse models that $\mathrm{FoxO} 3$ has a significant tumour-suppressor function in the context of Myc-driven lymphomagenesis. Although our data suggest a role for FoxO3-mediated inhibition of apoptosis in restraining Myc-driven tumour development, we suspect that loss of FoxO3 may also be affecting other tumour-suppressive functions for which FoxO1/4 cannot fully compensate. Of note, the tumour-suppressive activity of p53 does not involve its capacity to promote apoptosis or cell cycle arrest. ${ }^{54,55}$ 


\section{Materials and Methods}

Mice. Experimental protocols involving the use of mice were approved by the Walter and Eliza Hall Institute's Animal Ethics Committee. All mice were on a C57BL/6 background and were bred at the Walter and Eliza Hall Institute (WEHI). To generate $\mathrm{FoxO}^{-1-} \mathrm{MYC10}$ mice, $\mathrm{FoxO}^{+/-}$(ref. 21) females were crossed with MYC10 ${ }^{\text {hom32 }}$ males (i.e., homozygous for the MYC10 transgene) then offspring were interbred. FoxO3 ${ }^{-1-} \mathrm{E} \mu$-myc mice were produced by mating $\mathrm{FoxO}^{+1-}$ females with $E \mu-m y c^{33}$ males followed by interbreeding of offspring. Analysis was performed on healthy young mice (4 or 8 weeks of age) and cohorts of mice were aged to ethical end point.

Haemopoietic analysis. Blood counts and composition were determined using an ADVIA 2120 haematology analyser (Siemens, Erlangen, Germany). In addition, for preneoplastic analysis, the remaining blood was depleted of red blood cells using $0.168 \mathrm{M}$ ammonium chloride and cell composition determined by flow cytometry, as below. Single-cell suspensions were prepared from spleen, thymus, lymph nodes (axillary, brachial, inguinal) and bone marrow and leukocytes enumerated with a CASY Cell Counter (Scharfe System GmbH, Reutlingen, Germany). Cell composition was determined by staining with fluorochrome-labelled surface marker-specific monoclonal antibodies followed by fluorescence-activated cell sorting (FACS) analysis using an LSRI (BD Biosciences, Franklin Lakes, NJ, USA). Data were processed using FlowJo Version 9.3.2 (TreeStar, Ashland, OR, USA). The monoclonal antibodies, produced and labelled with fluorescein isothiocyanate (FITC), R-phycoerythrin or allophycocyanin at WEHI, were: RB68C5, anti-Gr1; MI/70, anti-Mac1; H129.19, anti-CD4; YTS169, anti-CD8; Ter119, anti-erythroid marker; RA3-6B2, anti-CD45R-B220; 5.1, anti-IgM; 11-26C, anti-IgD; T24-31, anti-Thy1.

Cell cycle analysis. Pre- $\mathrm{B}$ cells $\left(\mathrm{B}^{2} 2 \mathrm{O}^{+} \operatorname{lgM}{ }^{-} \lg \mathrm{D}^{-}\right)$were purified from the bone marrow of 4-week-old mice by flow cytometry, or by using CD19 MicroBeads (Miltenyi Biotech, Bergisch Gladbach, Germany) and MS columns (Miltenyi Biotech) according to the manufacturer's protocols. The Nicoletti assay ${ }^{56}$ was used for cell cycle analysis of the purified pre-B cells - cells were resuspended in $0.1 \%$ sodium citrate, $0.1 \%$ Triton $\mathrm{X}$ and $50 \mu \mathrm{g} / \mathrm{ml}$ propidium iodide (PI) and incubated for $30 \mathrm{~min}$ on ice before FACS analysis. Alternatively, mixed cell populations, such as bone marrow, were stained with surface markers for the population of interest before fixation and permeabilisation with the Transcription Factor Staining Buffer Set (eBioscience, San Diego, CA, USA). Cells were then stained with PI/RNase staining solution (Cell Signaling Technology, Danvers, MA, USA) for 30 min before analysis on an LSR II flow cytometer (BD Biosciences). Cell cycle profiles were characterised using FlowJo using the Watson pragmatic model (see above).

Survival assays. Thymocyte populations or pre-B cells isolated by flow cytometry were cultured at $0.2-0.5 \times 10^{6} \mathrm{cell} / \mathrm{s} / \mathrm{ml}$ in high-glucose Dulbecco's Modified Eagle's medium supplemented with $10 \%$ foetal calf serum (JRH Biosciences, Brooklyn, VIC, Australia), $50 \mu \mathrm{M}$ 2-mercaptoethanol (2-ME; Sigma-Aldrich, St Louis, $\mathrm{MO}, \mathrm{USA}$ ) and $100 \mu \mathrm{M}$ asparagine (Sigma-Aldrich) without additional cytokines. In addition, thymocytes were treated before culture with 1.25 Gy $\gamma$-irradiation. Cell viability was determined by staining with FITC-conjugated annexin $\mathrm{V}$ and PI followed by flow cytometry. Specific viability was calculated at each time point as (viability of treated cells/viability of untreated cells) $\times 100 \%$.

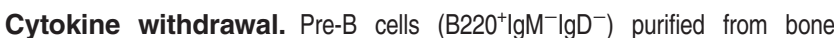
marrow by flow cytometry were cultured at a starting density of $1 \times 10^{6} / \mathrm{ml}$ in Iscove's modified Dulbecco's medium supplemented with 1x GlutaMAX, $1 \mathrm{mM}$ sodium pyruvate, $0.1 \mathrm{mM}$ nonessential amino acids, $10 \mathrm{mM}$ HEPES pH 7.4 (all media supplements from Life Technologies, Carlsbad, CA, USA), $50 \mu \mathrm{M}$ 2-ME, $10 \%$ foetal calf serum and $2 \%$ mIL-7 supernatant (produced by transfected $\times 63 / 0$ hybridoma cells) ${ }^{57}$ Cultures were split if required. After 5 days, cells were washed three times to remove IL-7, then replated at $0.3 \times 10^{6} / \mathrm{ml}$ with or without IL-7 for 2 days. Viability was determined by flow cytometry as above.

T-cell blasts were generated by stimulation of splenocytes $\left(2 \times 10^{6} / \mathrm{ml}\right)$ for 3 days with $1 \% \mathrm{mlL}-2$ supernatant ${ }^{57}$ and $2 \mu \mathrm{g} / \mathrm{ml}$ concanavalin A (Sigma-Aldrich) in cell culture medium as for survival assays above. Cells were then washed three times to remove concanavalin A and cultured with IL-2 alone for $24 \mathrm{~h}$. To set up the death assay, cells were washed three times to remove IL-2 then cultured with or without IL-2 for 2 days. Viability was determined by flow cytometry as above.
Cleaved caspase-3 immunohistochemistry. Spleens and lymph nodes from lymphoma-bearing mice were fixed in 10\% formalin then embedded in paraffin. Sections were stained for cleaved caspase-3 using the SignalStain Apoptosis (Cleaved Caspase-3) IHC Detection Kit (Cell Signaling Technology) according to the manufacturer's protocol. Stained slides were imaged (blinded as to genotype) using an Olympus BX43 microscope (Olympus, Tokyo, Japan) and Olympus DP72 camera at x200 magnification.

Immunoblotting. Protein extracts were prepared by lysis in RIPA buffer (300 mM NaCl, 2\% IGEPAL CA-630, 1\% deoxycholic acid, 0.2\% SDS, $100 \mathrm{mM}$ Tris- $\mathrm{HCl} \mathrm{pH}$ 8.0) containing complete ULTRA protease inhibitors (Roche, Basel, Switzerland). Western blots were carried out using $30 \mu \mathrm{g}$ total protein per sample run on NuPAGE Bis-Tris gels (Life Technologies) and transferred to nitrocellulose membranes with an iBlot (Life Technologies) according to the manufacturer's protocols. Blots were probed with the following antibodies: p53 (FL-393, Santa Cruz Biotechnology, Santa Cruz, CA, USA); p19ARF (p19ARF exon 2, Rockland, Gilbertsville, PA, USA); Mdm2 (C-18, Santa Cruz Biotechnology); FoxO3 (75D8, Cell Signaling Technology); FoxO1 (C29H4, Cell Signaling Technology); and $\beta$-actin (clone AC-74, Sigma-Aldrich).

Statistical analysis. GraphPad Prism (Version 6.0d, GraphPad Software, San Diego, CA, USA) was used to graph and statistically analyse data. Student's t-test (an unpaired two-tailed t-test) or the log-rank (Mantel-Cox) test, for Kaplan-Meier mouse survival curves, were used to determine statistical significance.

\section{Conflict of Interest}

The authors declare no conflict of interest.

Acknowledgements. We thank our institute colleagues A Strasser, MJ Herold and Steve Nutt for useful discussions; J Mansheim, K Hughes, S Allan, M Robati and $\mathrm{J}$ Corbin for excellent technical assistance; and the institute's Flow Cytometry Facility for skilled support. This work was supported by the NHMRC (Australia) program grants 461221; 1016647; NCI grant CA43540; Leukemia and Lymphoma Society Specialized Center for Research Grant 7015-02; an NHMRC Career Development Award (CJV); and infrastructure support to WEHI from the NHMRC Independent Research Institute Infrastructure Support Scheme (IRISS) and the Victorian State Government Operational Infrastructure Support (OIS).

\section{Author contributions}

CJV and SC conceived the studies, planned experiments, analysed data and wrote the manuscript. CJV performed the experiments. NM provided mice and intellectual input.

1. van der Horst $A$, Burgering BM. Stressing the role of FoxO proteins in lifespan and disease. Nat Rev Mol Cell Biol 2007; 8: 440-450.

2. Lam EW, Brosens JJ, Gomes AR, Koo CY. Forkhead box proteins: tuning forks for transcriptional harmony. Nat Rev Cancer 2013; 13: 482-495.

3. Dijkers PF, Medema RH, Lammers JJ, Koenderman L, Coffer PJ. Expression of the proapoptotic Bcl-2 family member Bim is regulated by the forkhead transcription factor FKHRL1. Curr Biol 2000; 10: 1201-1204.

4. Dijkers PF, Birkenkamp KU, Lam EW, Thomas NS, Lammers JW, Koenderman L et al. FKHR-L1 can act as a critical effector of cell death induced by cytokine withdrawal: protein kinase B-enhanced cell survival through maintenance of mitochondrial integrity. $J$ Cell Biol 2002; 156: 531-542.

5. Stahl M, Dijkers PF, Kops GJ, Lens SM, Coffer PJ, Burgering BM et al. The forkhead transcription factor FoxO regulates transcription of $\mathrm{p} 27^{\mathrm{Kip} 1}$ and Bim in response to IL-2. $\mathrm{J}$ Immunol 2002; 168: 5024-5031.

6. Medema RH, Kops GJ, Bos JL, Burgering BM. AFX-like Forkhead transcription factors

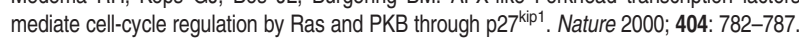

7. Alvarez B, Martinez AC, Burgering BM, Carrera AC. Forkhead transcription factors contribute to execution of the mitotic programme in mammals. Nature 2001; 413: 744-747.

8. Ferber EC, Peck B, Delpuech O, Bell GP, East P, Schulze A. FOXO3a regulates reactive oxygen metabolism by inhibiting mitochondrial gene expression. Cell Death Differ 2012; 19: 968-979.

9. van der Vos KE, Eliasson P, Proikas-Cezanne T, Vervoort SJ, van Boxtel R, Putker $\mathrm{M}$ et al. Modulation of glutamine metabolism by the $\mathrm{PI}(3) \mathrm{K}-\mathrm{PKB}-\mathrm{FOXO}$ network regulates autophagy. Nat Cell Biol 2012; 14: 829-837.

10. Eijkelenboom A, Burgering BM. FOXOs: signalling integrators for homeostasis maintenance. Nat Rev Mol Cell Biol 2013; 14: 83-97. 
11. Brunet A, Bonni A, Zigmond MJ, Lin MZ, Juo P, Hu LS et al. Akt promotes cell survival by phosphorylating and inhibiting a Forkhead transcription factor. Cell 1999; 96: 857-868.

12. Matsuzaki H, Daitoku H, Hatta M, Tanaka K, Fukamizu A. Insulin-induced phosphorylation of FKHR (Foxo1) targets to proteasomal degradation. Proc Natl Acad Sci USA 2003; 100: 11285-11290

13. Essers MA, Weijzen S, de Vries-Smits AM, Saarloos I, de Ruiter ND, Bos JL et al. FOXO transcription factor activation by oxidative stress mediated by the small GTPase Ra and JNK. EMBO J 2004; 23: 4802-4812.

14. Furuyama T, Nakazawa T, Nakano I, Mori N. Identification of the differential distribution patterns of mRNAs and consensus binding sequences for mouse DAF-16 homologues. Biochem J 2000; 349: 629-634.

15. Jacobs FM, van der Heide LP, Wijchers PJ, Burbach JP, Hoekman MF, Smidt MP. FoxO6 a novel member of the FoxO class of transcription factors with distinct shutling dynamics. J Biol Chem 2003; 278: 35959-35967.

16. Dejean AS, Hedrick SM, Kerdiles YM. Highly specialized role of Forkhead box 0 transcription factors in the immune system. Antioxid Redox Signal 2011; 14: 663-674.

17. Hosaka T, Biggs WH 3rd, Tieu D, Boyer AD, Varki NM, Cavenee WK et al. Disruption of forkhead transcription factor (FOXO) family members in mice reveals their functional diversification. Proc Natl Acad Sci USA 2004; 101: 2975-2980.

18. Salih DA, Rashid AJ, Colas D, de la Torre-Ubieta L, Zhu RP, Morgan AA et al. FoxO6 regulates memory consolidation and synaptic function. Genes Dev 2012; 26: 2780-2801.

19. Nakae J, Biggs WH 3rd, Kitamura T, Cavenee WK, Wright CV, Arden KC et al. Regulation of insulin action and pancreatic beta-cell function by mutated alleles of the gene encoding forkhead transcription factor Foxo1. Nat Genet 2002; 32: 245-253.

20. Castrillon DH, Miao L, Kollipara R, Horner JW, DePinho RA. Suppression of ovarian follicle activation in mice by the transcription factor Foxo3a. Science 2003; 301: 215-218.

21. Miyamoto K, Araki KY, Naka K, Arai F, Takubo K, Yamazaki S et al. Foxo3a is essential for maintenance of the hematopoietic stem cell pool. Cell Stem Cell 2007; 1: 101-112.

22. Yalcin S, Zhang X, Luciano JP, Mungamuri SK, Marinkovic D, Vercherat $C$ et al. Foxo3 is essential for the regulation of ataxia telangiectasia mutated and oxidative stress-mediated homeostasis of hematopoietic stem cells. J Biol Chem 2008; 283: 25692-25705.

23. Warr MR, Binnewies M, Flach J, Reynaud D, Garg T, Malhotra R et al. FOXO3A directs a protective autophagy program in haematopoietic stem cells. Nature 2013; 494: 323-327.

24. Altomare DA, Testa JR. Perturbations of the AKT signaling pathway in human cancer Oncogene 2005; 24: 7455-7464

25. Paik JH, Kollipara R, Chu G, Ji H, Xiao Y, Ding Z et al. FoxOs are lineage-restricted redundant tumor suppressors and regulate endothelial cell homeostasis. Cell 2007; 128: 309-323

26. Bouchard C, Lee S, Paulus-Hock V, Loddenkemper C, Eilers M, Schmitt CA. FoxO transcription factors suppress Myc-driven lymphomagenesis via direct activation of Arf. Genes Dev 2007; 21: 2775-2787.

27. Bouchard C, Marquardt J, Bras A, Medema RH, Eilers M. Myc-induced proliferation and transformation require Akt-mediated phosphorylation of FoxO proteins. EMBO J 2004; 23 : 2830-2840.

28. Amente S, Zhang J, Lavadera ML, Lania L, Avvedimento EV, Majello B. Myc and PI3K/AKT signaling cooperatively repress FOXO3a-dependent PUMA and GADD45a gene expression. Nucleic Acids Res 2011; 39: 9498-9507.

29. Eijkelenboom A, Mokry M, de Wit E, Smits LM, Polderman PE, van Triest MH et al. Genomewide analysis of $\mathrm{FOXO} 3$ mediated transcription regulation through RNA polymerase I profiling. Mol Syst Biol 2013; 9: 638

30. Delpuech O, Griffiths B, East P, Essafi A, Lam EW, Burgering B et al. Induction of Mxi1-SR alpha by $\mathrm{FOXO} 3 \mathrm{a}$ contributes to repression of Myc-dependent gene expression. $\mathrm{Mol} \mathrm{Cell}$ Biol 2007; 27: 4917-4930.

31. Smith DP, Bath ML, Harris AW, Cory S. T-cell lymphomas mask slower developing B-lymphoid and myeloid tumors in transgenic mice with broad hematopoietic expression of MYC. Oncogene 2005; 24: 3544-3553.

32. Smith DP, Bath ML, Metcalf D, Harris AW, Cory S. MYC levels govern hematopoietic tumor type and latency in transgenic mice. Blood 2006; 108: 653-661.

33. Adams JM, Harris AW, Pinkert CA, Corcoran LM, Alexander WS, Cory S et al. The c-myc oncogene driven by immunoglobulin enhancers induces lymphoid malignancy in transgenic mice. Nature 1985; 318: 533-538.

34. Harris AW, Pinkert CA, Crawford M, Langdon WY, Brinster RL, Adams JM. The E $\mu-m y c$ transgenic mouse: a model for high-incidence spontaneous lymphoma and leukemia of early B cells. J Exp Med 1988; 167: 353-371.

35. Michalak EM, Jansen ES, Happo L, Cragg MS, Tai L, Smyth GK et al. Puma and to a lesser extent Noxa are suppressors of Myc-induced lymphomagenesis. Cell Death Differ 2009; 16 : 684-696.

36. Campbell KJ, Bath ML, Turner ML, Vandenberg CJ, Bouillet P, Metcalf D et al. Elevated Mcl-1 perturbs lymphopoiesis, promotes transformation of hematopoietic stem/progenito cells, and enhances drug resistance. Blood 2010; 116: 3197-3207.
37. Strasser A, Harris AW, Bath ML, Cory S. Novel primitive lymphoid tumours induced in transgenic mice by cooperation between myc and bcl-2. Nature 1990; 348: 331-333.

38. Rosenbaum $\mathrm{H}$, Harris AW, Bath ML, McNeall J, Webb E, Adams JM et al. An Em-V-ab transgene elicits plasmacytomas in concert with an activated myc gene. EMBO J 1990; 9 : 897-905.

39. Herold MJ, Rohrbeck L, Lang MJ, Grumont R, Gerondakis S, Tai L et al. Foxo-mediated Bim transcription is dispensable for the apoptosis of hematopoietic cells that is mediated by this BH3-only protein. EMBO Rep 2013; 14: 992-998.

40. Dejean AS, Beisner DR, Ch'en IL, Kerdiles YM, Babour A, Arden KC et al. Transcription factor Fox03 controls the magnitude of $\mathrm{T}$ cell immune responses by modulating the function of dendritic cells. Nat Immunol 2009; 10: 504-513.

41. Yalcin S, Marinkovic D, Mungamuri SK, Zhang X, Tong W, Sellers R et al. ROS-mediated amplification of $A K T / m T O R$ signalling pathway leads to myeloproliferative syndrome in Foxo3(-/-) mice. EMBO J 2010; 29: 4118-4131.

42. Kang H, Corr M, Mansson R, Welinder E, Hedrick SM, Stone EL. Loss of murine FOXO3 in cells of the myeloid lineage enhances myelopoiesis but protects from K/BxN-serum transferinduced arthritis. PLoS One 2015; 10: e0126728.

43. Hinman RM, Nichols WA, Diaz TM, Gallardo TD, Castrillon DH, Satterthwaite AB. Foxo3-/mice demonstrate reduced numbers of pre-B and recirculating $B$ cells but normal splenic $B$ cell sub-population distribution. Int Immunol 2009; 21: 831-842.

44. Bakker WJ, van Dijk TB, Parren-van Amelsvoort M, Kolbus A, Yamamoto K, Steinlein P et al. Differential regulation of Foxo3a target genes in erythropoiesis. Mol Cell Biol 2007; 27: 3839-3854.

45. Marinkovic D, Zhang X, Yalcin S, Luciano JP, Brugnara C, Huber T et al. Foxo3 is required for the regulation of oxidative stress in erythropoiesis. J Clin Invest 2007; 117: 2133-2144.

46. Langdon WY, Harris AW, Cory S, Adams JM. The c-myc oncogene perturbs B lymphocyte development in E $\mu-m y c$ transgenic mice. Cell 1986; 47: 11-18.

47. Eilers M, Eisenman RN. Myc's broad reach. Genes Dev 2008; 22: 2755-2766.

48. Kops GJ, Medema RH, Glassford J, Essers MA, Dijkers PF, Coffer PJ et al. Control of cell cycle exit and entry by protein kinase B-regulated forkhead transcription factors. Mol Cell Biol 2002; 22: 2025-2036.

49. Evan GI, Wyllie AH, Gilbert CS, Littlewood TD, Land H, Brooks M et al. Induction of apoptosis in fibroblasts by c-myc protein. Cell 1992; 69: 119-128.

50. Evan GI, Vousden KH. Proliferation, cell cycle and apoptosis in cancer. Nature 2001; 411: 342-348.

51. Eischen CM, Weber JD, Roussel MF, Sherr CJ, Cleveland JL. Disruption of the ARF-Mdm2p53 tumor suppressor pathway in Myc-induced lymphomagenesis. Genes Dev 1999; 13: 2658-2669.

52. Ekoff M, Kaufmann T, Engström M, Motoyama N, Villunger A, Jönsson Jl et al. The BH3-only protein Puma plays an essential role in cytokine deprivation-induced apoptosis of mast cells. Blood 2007; 110: 3209-3217.

53. Sherr CJ. The INK4a/ARF network in tumour suppression. Nat Rev Mol Cell Biol 2001; 2 : 731-737.

54. Brady CA, Jiang D, Mello SS, Johnson TM, Jarvis LA, Kozak MM et al. Distinct p53 transcriptional programs dictate acute DNA-damage responses and tumor suppression. Cell 2011; 145: 571-583.

55. Valente LJ, Gray DH, Michalak EM, Pinon-Hofbauer J, Egle A, Scott CL et al. p53 efficiently suppresses tumor development in the complete absence of its cell-cycle inhibitory and proapoptotic effectors p21, Puma, and Noxa. Cell Rep 2013; 3: 1339-1345.

56. Nicoletti I, Migliorati G, Pagliacci MC, Grignani F, Riccardi C. A rapid and simple method for measuring thymocyte apoptosis by propidium iodide staining and flow cytometry. J Immunol Meth 1991; 139: 271-279.

57. Karasuyama $\mathrm{H}$, Melchers $\mathrm{F}$. Establishment of mouse cell lines which constitutively secrete large quantities of interleukin 2, 3, 4 or 5 , using modified cDNA expression vectors. Eur J Immunol 1988; 18: 97-104.

(i) Cell Death and Disease is an open-access journal published by Nature Publishing Group. This work is licensed under a Creative Commons Attribution 4.0 International License. The images or other third party material in this article are included in the article's Creative Commons license, unless indicated otherwise in the credit line; if the material is not included under the Creative Commons license, users will need to obtain permission from the license holder to reproduce the material. To view a copy of this license, visit http://creativecommons.org/licenses/by/4.0/ 